\title{
The heritability of acceptability in South African Merino sheep
}

\author{
G.J. Erasmus ${ }^{1}$, F.W.C. Neser ${ }^{1 \#}$, J.B. van Wyk ${ }^{1}$ and J.J. Olivier ${ }^{2}$ \\ ${ }^{1}$ Department of Animal Science, University of the Free State, Box 339, Bloemfontein 9300, South Africa. \\ ${ }^{2}$ ARC, Animal Improvement Institute, Middelburg EC 5900, South Africa
}

\begin{abstract}
Selection for production and reproduction in South African Merino sheep is always combined with selection based on visual appraisal and will, in all probability, remain so for many years to come. Heritabilities for acceptability were estimated using a threshold model to analyse data from two parent Merino studs. Effects included in the analysis were sex, birth status, age of dam and year of birth. An acceptable animal was defined as one that was present in the stud at 18 months of age, implying that such an animal would either be retained or sold for breeding purposes. This provided one threshold and two classes (acceptable or not acceptable). Records from the two studs used comprised 3011 progeny of 31 sires and 6495 progeny of 70 sires. Error variance was taken as unity and heritability estimated as $h^{2}=4 \sigma_{s}^{2} / 1+\sigma_{s}^{2}$ where $\sigma^{2}$ is the sire variance. Heritability estimates were 0.210 and 0.448 . The results suggest that selection improvement for acceptability is possible, and that breeding values for this trait should be supplied for AI sires.
\end{abstract}

Keywords: acceptability, heritability, Merino sheep, threshold model, breeding, genetics

\#Author to whom the correspondence should be addressed. E-mail: NeserFW@ sci.uovs.ac.za

\section{Introduction}

For most livestock breeds in South Africa, selection pressure on visual assessment is normally so high that few animals remain for selection based on measured productive and reproductive performance. This is probably the single most important factor limiting the effective application of performance testing. The proportion of animals acceptable for breeding purposes is of major economic importance to stud breeders since the sale of animals for premium prices is their main source of profit. "Acceptability" is a very complex trait with many components, but the most important is probably overall visual acceptability. This can, however, also be said of most traits normally included in selection programmes, especially when their physiological causal components are taken into account. The concept of a threshold trait, which clearly applies in this case, does not rule out the possibility of several continuous polygenic causal traits contributing to the variance underlying the distinct expressed classes and thresholds. The question is whether the genetic improvement of acceptability can be accelerated using modern scientific techniques. The aim of this study was to estimate the heritability of this trait.

\section{Materials and methods}

Data from the Grootfontein Merino stud and a commercial parent Merino stud were used. Both studs are considered to be "parent studs" in the sense that they effectively use only own-bred sires. The data-set comprised records of 3011 progeny of 31 sires from the Grootfontein stud and 6495 progeny of 70 sires from the commercial parent Merino stud. Acceptability was defined as those properties that resulted in the animal as still being present in the stud at 18 months of age. It was argued the presence of an animal at this age was indicative of an acceptable type and that such an animal would either be kept in the stud or sold for breeding purposes.

A threshold sire model was fitted using the GFCAT set of programmes of Konstantinov et al. (1994) which is based on the procedure suggested by Gianola \& Foulley (1983). The definition provided one threshold and two classes (acceptable and not acceptable). Four "fixed" effects, viz. sex, birth status, age of dam (five classes) and year of birth (nine years) were included. Error variance was taken as unity and the heritability estimated as $h^{2}=4 \sigma_{\mathrm{s}}^{2} / 1+\sigma_{\mathrm{s}}^{2}$, where $\sigma_{\mathrm{s}}^{2}$ is the sire variance. 


\section{Results and discussion}

The solutions of the fixed effects were given in units of residual standard deviations. Their actual values are therefore not very informative and are thus not supplied. It can, however, be stated that, as expected, ewes had a higher acceptability than rams, the standard set for rams being higher. Single-born lambs were more acceptable than multiples in the commercial stud, but preference was given to multipleborn lambs in the Grootfontein stud in an effort to improve fecundity. Acceptability generally increased with age of dam. It is interesting that the differences in solutions of the different classes of effects were generally far smaller in the Grootfontein stud than the commercial stud, possibly indicating a more efficient adjustment for those non-genetic effects. The fact that the differences in solutions can be explained suggests that the definition applied to acceptability is reasonable.

The heritability estimates were 0.210 for Grootfontein and 0.448 for the commercial stud. Their corresponding highest $v s$. lowest predicted breeding values were $0.394 v s .-0.333$ and $0.548 v s$. -0.810 (also in residual standard deviation units) respectively. This indicates that acceptability can be improved by selection.

\section{Conclusions}

Acceptability is a trait of great concern to stud breeders, and the possibility of genetic improvement is encouraging. Although this study and the results obtained should be seen as preliminary, the routine estimation of breeding values can be safely recommended, at least for AI sires. Similar studies with other livestock breeds should also be carried out. The possibility of using more than one threshold (different grades of acceptability) and the incorporation of linear-type classification should also be investigated. A note of caution should be sounded regarding the suitability of data for this type of analysis. In some cases preference could be given to the progeny of certain sires - perhaps those for which high prices were paid or show champions. This will lead to upward-biased heritability estimates. Pooling of data across studs will probably result in problems and this aspect should be investigated thoroughly.

\section{References}

Gianola, D. \& Foulley, J.L., 1983. Sire evaluation for ordered data with a threshold model. Genet. Sel. Evol. $15,201-224$.

Konstantinov, K.V., Erasmus, G.J. \& Van Wyk, J.B., 1994. Evaluation of Dormer sires for litter size and lamb mortality using a threshold model. S. Afr. J. Anim. Sci. 24, 119-121. 